\title{
Comportamiento salarial de las profesiones en salud, Huila. 2013
}

\section{How salaries change among health professions in Huila, 2013}

\author{
Kiara Bustos' ${ }^{1}$ Edson Castro', Marly Ceballos', Lilian Londoño', Cristina Peña', \\ Yesica Pérez', Camila Rojas', Katherine Serrano', Maickol Tirado', Dolly Arias²
}

\begin{abstract}
Resumen
Introducción: Según la Corte Constitucional es derecho esencial del trabajador la remuneración por los servicios prestados; ésta ha de ser adecuada al esfuerzo, preparación, experiencia, conocimientos y tiempo de dedicación. Objetivo: Establecer el comportamiento salarial de las profesiones en salud. Métodos: estudio descriptivo, cuantitativo, transversal; población conformada por 1060 profesionales en salud de seis IPS huilenses; la información se obtuvo mediante cuestionario administrado por los investigadores; se procesó en software Excel 2013 y en el análisis se utilizó estadística descriptiva. Resultados: $60 \%$ de los profesionales se concentran en la IPS de mayor nivel de complejidad; porcentaje similar pertenece a la disciplina que históricamente ha ostentado poder en salud; los salarios son bajos, hallazgo acentuado en carreras femeninas; no existen criterios estandarizados para definir remuneración. $38,2 \%$ tiene posgrado, de éstos $91.6 \%$ pertenecen a la disciplina con mayor reconocimiento económico; el salario mensual de las profesiones con posgrado varió de $\$ 2.635 .135$ a $\$ 11.800 .000$, promedio $\$ 5.247 .823$, mediana $\$ 5.638 .000$, y moda $\$ 5.638 .000 .27,5 \%$ son empleados de planta, $14 \%$ por prestación de servicios y $58,5 \%$ son vinculados a través de agremiación sindical. Conclusión: hay discriminación e inequidad en distribución y remuneración de las profesiones en salud; características contrarias a la política de desarrollo de talento humano formulada en el Llamado a la Acción de Toronto. Recomendación: Gestionar la aprobación de escalafón salarial equitativo y justo para las profesiones en salud.
\end{abstract}

Palabras clave: salario, profesiones en salud, servicios de salud.

\begin{abstract}
Introduction: According to the Constitutional Court, remuneration for services rendered is a worker's basic right. Salaries should be appropriate for the effort, preparation, experience, knowledge and time commitment put in. Objective: Evaluate the salaries of health professions. Method: A descriptive, quantitative and transversal study, using a sample of 1060 health professionals in six health institutions in Huila. Information was collected using a survey administered by the researchers, processed using Excel 2013 and results were analysed statistically and descriptively. Results: $60 \%$ of the professionals were in the most comprehensive hospital (providing the widest range of care and treatment options); a similar percentage belong to the discipline which has historically been the most important in the health system. The salaries are low, something which is accentuated among women. There are no standardised criteria to determine remuneration. $32.8 \%$ have a postgraduate qualification, of whom $91.6 \%$ belong to the discipline with greater economic recognition. The monthly salary of the health professionals varied from $\$ 2.635 .135$ to $\$ 11.800 .000$, an average of $\$ 5.247 .823$, median of $\$ 5.638 .000$ and mode of $\$ 5.368 .000$. $27.5 \%$ have a permanent contract, $14 \%$ have temporary contracts and $58.5 \%$ are contracted through unions. Conclusion: There is discrimination and inequality in the distribution and remuneration in health professions. This goes against the call for development of human talent formulated in the Toronto Call to
\end{abstract}

1. Enfermeras(os) en formación. programa de enfermería, Facultad de salud, Universidad Surcolombiana.

2. Ph.D., Profesora Titular Programa de Enfermería. Universidad Surcolombiana de Neiva, Colombia.

Correspondencia: Dolly Arias. Correo electrónico: dolaria@usco.edu.co

Recibido: 13/06/2014-Revisado: 04/10/2015-Aceptado: 29/12/2015 
Action. Recommendation: Manage the approval of a balanced and fair salary scale for health care professions.

Key words: salary, health professions, health services.

\section{Introduccion}

La remuneración de las profesiones en salud es un tema de preocupación en ascenso, máxime si se tiene en cuenta características propias del momento: tercerización de los servicios de salud, bajos salarios, reestructuraciones constantes que ocasionan inestabilidad laboral, sobrecarga de trabajo, falta de seguridad social, desconocimiento del ejercicio de la libre asociación y negociación colectiva ${ }^{1}$, aspectos característicos del sistema de salud colombiano que determina, en gran parte, la crisis de los recursos humanos en salud. Crisis que ha sido analizada en diferentes instancias: en mayo de 2004, la Asamblea Mundial de la Salud (AMS) ya había pedido medidas para mitigar los efectos negativos de la migración internacional de los trabajadores de la salud a través de la resolución WHA57. En diciembre de ese año, la Iniciativa Conjunta de Aprendizaje que reunió a varios expertos y defensores en el campo, emitió un informe pidiendo la atención global a la crisis de RHS en los países. En el Informe Sobre la Salud en el Mundo (ISSM) 2006 se identificaron 57 países en crisis de recursos humanos en salud (RHS), incluido Colom$\mathrm{bia}^{2}$, crisis que al parecer coadyuvó en la redacción del "Llamado a la Acción de Toronto", en el que se inició el trabajo hacia una década de Recursos Humanos en Salud para las Américas 2006-2015².

El salario más alto de los países Latinoamericanos, no alcanza al valor mínimo observado en Norteamérica y Europa. En Colombia, no existe una escala de remuneración equitativa para las profesiones en salud, tampoco se ha establecido la diferenciación de pagos de acuerdo al nivel de formación y experiencia, hecho que ha permitido que se presenten desigualdades y abusos por parte de los empleadores; según Restrepo y Ortiz ${ }^{4}$, se evidencia que el nivel de ingreso para el programa de medicina es $16 \%$ superior al de enfermería. En el Huila, Arias Dolly ${ }^{5}$, encontró que $69.4 \%$ de profesionales de Enfermería devengan entre dos y cuatro Salarios Mínimos Mensuales Legales Vigentes (SMMLV), con un promedio de $\$ 1.600 .000$ en contraste con salarios de otras profesiones cuyos ingresos oscilan entre $\$ 3.605 .000$ y $\$ 5.150 .000$. Al parecer, uno de los factores que influyen en la inequidad salarial de las profesiones en salud es la condición de género y edad. En las actividades del sector salud predomina la ocupación femenina y por cada peso que recibe una mujer, un hombre recibe $1,84^{6}$. Las leyes 100 de 1993, 1122 de 2007, 1438 de 2011, tampoco su reglamentación, han incluido aspectos importantes para una atención de calidad en salud como son la estabilidad y la remuneración del talento humano. Existen evidencias de que sí es posible la equidad en la compensación económica de profesionales de áreas similares, un claro ejemplo lo encontramos en el sector educativo ${ }^{7}$. Abogar por un escalafón en el que se dé el mismo trato a todas las profesiones en salud es una propuesta incluyente y pertinente, que se puede alcanzar con voluntad política y una estructura organizativa fuerte. Con base en lo anteriormente expuesto se ha formulado el siguiente interrogante: ¿Cuál es el comportamiento salarial de las profesiones en salud de seis instituciones prestadoras de servicios de salud del Huila, 2013?

Se espera que los resultados ayuden en la constitución de una masa crítica, reflexiva y analítica en el sector de la salud en procura del mejoramiento de condiciones laborales y mayores oportunidades para el desarrollo personal y profesional.

\section{Materiales y métodos}

Estudio descriptivo, cuantitativo, de corte transversal. No se tomó muestra, Población conformada por 1060 personas correspondientes a 13 profesiones en salud, de seis IPS en cuatro municipios del departamento del Huila. La información se recolectó a través de un cuestionario semi-estructurado, validado por expertos, con preguntas abiertas, administrado por los investigadores en entrevista realizada a los coordinadores de las oficinas de talento humano de cada institución; se procesó mediante software Excel 2013 y en el análisis se utilizó estadística descriptiva.

No se realizó intervención o modificación intencionada de las variables biológicas, fisiológicas, psicológicas o sociales de los participantes, razón por la cual fue un estudio sin riesgos (Resolución 8430 de 1993 CITA); contó con el aval del Comité de Ética de la Facultad de Salud y el asentimiento de las entidades participantes.

\section{Resultados}

En las seis Instituciones Prestadoras de Servicios (IPS) visitadas, trabajan 1060 profesionales en salud, distribuidos así: (Tabla 1).

Se infiere que a mayor nivel de complejidad, las instituciones de salud requieren un mayor número de profesionales para dar respuesta a la demanda de servicios, razón por la cual se evidencia que cerca del $80 \%$ de los profesionales se encuentran concentrados en las IPS de III y IV nivel de complejidad.

Se observa que el mayor número de profesionales en salud de las seis IPS son médicos, seguido de enfermeros y fisioterapeutas (Figura 1). En la IPS 1 se ubica 60\% del total de médicos, enfermeras y fisioterapeutas; $38.2 \%$ del total de la población tiene especialización o maestría, aclarando que las especialidades médicas clínicas son homologables a maestrías. De estos últimos, 91,6\% son médicos, 5,2\% enfermeros, 
Tabla 1. Porcentaje de profesionales en salud por IPS. Huila, 2013.

\begin{tabular}{lcc}
\hline Número de IPS & $\begin{array}{c}\text { Nivel de } \\
\text { complejidad }\end{array}$ & $\begin{array}{c}\text { Porcentaje de } \\
\text { profesionales }\end{array}$ \\
\hline 1 & III y IV & 57,2 \\
2 & II y III & 18,8 \\
3 & II & 16,4 \\
4 & I & 4,2 \\
5 & I & 2,5 \\
6 & I & 0,9 \\
\hline
\end{tabular}

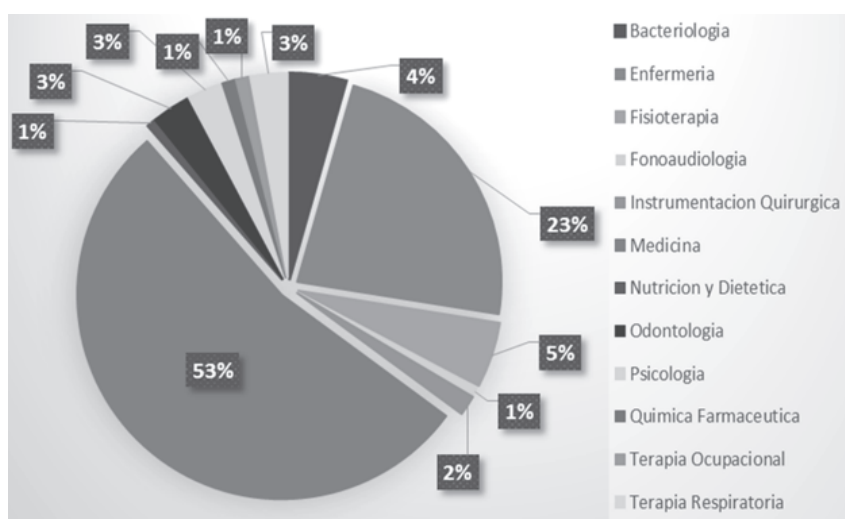

Figura 1. Porcentaje de profesionales en salud de seis IPS del Huila, 2013.
1,7\% odontólogos, $1 \%$ bacteriólogos y $0,5 \%$ psicólogos; en las otras profesiones no se reportaron títulos de posgrado.

$27,5 \%$ de los profesionales en salud son empleados de planta, 14\% están vinculados por prestación de servicios y $58,5 \%$ a través de agremiación sindical. Bacteriología, Fonoaudiología, Medicina y Terapia ocupacional registran el mayor porcentaje de profesionales de planta, vinculación predominante en la IPS privada. Más del $70 \%$ de profesionales de Enfermería, Instrumentación quirúrgica, Terapia respiratoria y Fisioterapia prestan sus servicios a través de agremiación sindical. (Tabla 2).

Existe una razón de 2.9 a uno entre el salario mensual máximo y el mínimo de las profesiones de pregrado de planta, lo cual indica que quienes perciben el primero ganan casi tres veces más que los segundos. Medicina, Química farmacéutica y Odontología son las mejor remuneradas en contraste con Psicología, Instrumentación quirúrgica y Fonoaudiología que tienen menor reconocimiento.

Los profesionales vinculados por prestación de servicios con mayores salarios son Medicina, Nutrición y dietética y Química farmacéutica mientras que Fisioterapia, Enfermería y Odontología reciben la remuneración más baja; en este grupo la razón es de cuatro a uno. Los contratados a través de agremiación sindical con reconocimiento económico más alto son Medicina, Química farmacéutica y Odontología, mientras que Instrumentación quirúrgica, Fonoaudiología y Terapia ocupacional tienen los salarios más bajos con una razón de 2.5 a uno respectivamente. (Tabla 3).

Tabla 2. Rangos salariales de profesiones en salud con pregrado.

\section{Pregrado}

\begin{tabular}{lccc}
\cline { 2 - 4 } & Planta & Prestación de servicios & Agremiación sindical \\
\hline Salario máximo & 3.942 .000 & 6.000 .000 & 27.040 \\
Salario mínimo & 1.352 .574 & 1.500 .000 & 10.810 \\
Mediana & 2.376 .000 & 2.500 .000 & 13.190 \\
Promedio & 2.731 .571 & 2.724 .585 & 14.971 \\
\hline
\end{tabular}

Tabla 3. Rangos salariales de profesiones en salud con posgrado.

\section{Postgrado}

\begin{tabular}{lccc}
\cline { 2 - 4 } & Planta & Prestación de servicios & $\begin{array}{c}\text { Agremiación sindical } \\
\text { (valor hora) }\end{array}$ \\
\hline Salario máximo & 6.884 .817 & 11.800 .000 & 178.226 \\
Salario mínimo & 2.635 .135 & 6.000 .000 & 15.700 \\
Mediana & 5.638 .000 & 6.500 .000 & 64.000 \\
Promedio & 5.190 .124 & 7.360 .000 & 62.013 \\
Moda & 5.638 .000 & 6.000 .000 & 66.950 \\
\hline
\end{tabular}


Los profesionales posgraduados de planta con mayores salarios ganan 4.2 veces más que quienes reciben la remuneración más baja. El grupo de la disciplina mayoritaria con formación a este nivel percibe la compensación económica más alta, seguida con amplia diferencia, de los odontólogos y las enfermeras.

En la contratación por prestación de servicios, vínculo casi exclusivo de los médicos especialistas, la remuneración más favorable corresponde a la profesión predominante y la menos próspera a las enfermeras con posgrado. En los vinculados a través de agremiación sindical, el valor hora menor corresponde a Psicología, Enfermería y Bacteriología. Se encontró que profesionales con especialización clínica con iguales condiciones laborales tienen una diferencia salarial amplia. Es así como una Enfermera que trabaja 240 horas/mes recibe $\$ 5.225 .173$ mientras que otra profesión con 202 horas/mes devenga $\$ 25.123 .144$, casi cinco veces más.

El salario más alto de los directivos, registrado en la única IPS privada, es 3.9 veces superior al más bajo. Todos los gerentes son hombres, tres pertenecen a la profesión predominante, dos son odontólogos y uno es del área de las ciencias administrativas. (Figura 2).

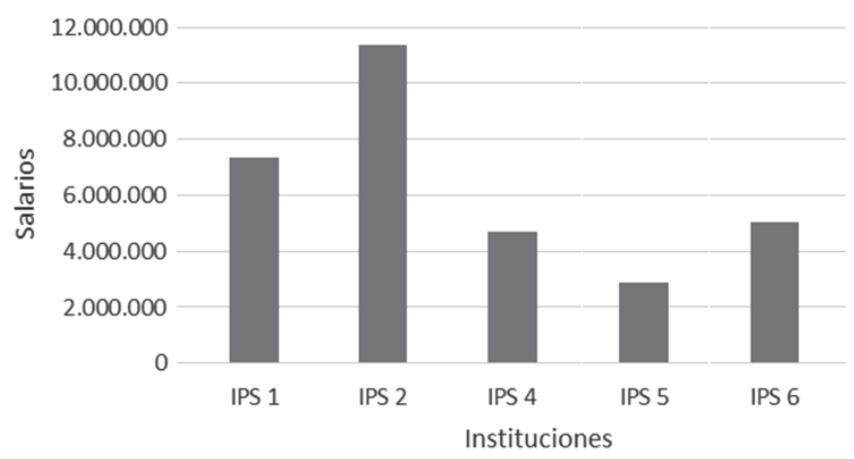

Figura 2. Asignación Salarial de los Gerentes de seis IPS del Huila, 2013.

Se encontró que no hay criterios unificados para la determinación de salarios de las profesiones en salud, tampoco de los gerentes; las IPS cinco y seis refirieron tener como pauta el Decreto 1029 del 2013, la IPS uno se basa en el Decreto 785 de 2005 y la IPS tres en la Ordenanza No. 031 del 2013 de la Asamblea Departamental del Huila. Las IPS cuatro y cinco se rigen por parámetros establecidos por los concejos municipales, y la IPS dos define el plan de cargos y salarios con base en la reglamentación anual de acuerdo a la inflación. En la IPS seis además del Decreto antes referido, se tiene en cuenta la disponibilidad de recursos económicos institucionales.

\section{Discusión}

La presencia mayoritaria de la misma disciplina en todas las instituciones puede estar relacionada con el modelo biologista de atención colombiano centrado en la enferme- dad, su curación y el papel protagónico que le han dado a este profesional en el sistema de salud del país ${ }^{8}$. En Bulgaria, Portugal y Turquía hay un médico por cada enfermera; en Noruega y Reino Unido la relación es de uno a cinco $^{9}$; en Canadá y Estados Unidos de uno a cuatro. Chile, Salvador, México y Perú, cuentan con más médicos que enfermeros; en Colombia para el año 2011 había dos médicos y una enfermera por cada 1000 habitantes ${ }^{10}$.

En general, los salarios de las profesiones en salud son bajos en relación a la preparación, experiencia y tiempo de dedicación, hallazgo acentuado en las carreras femeninas; existe disparidad en la asignación básica mensual entre profesiones y al interior de las mismas, con razones que van desde 2.9 a uno hasta cinco a uno., Diferencia que es más dramática al comparar los profesionales con título de posgrado, convirtiéndose en una circunstancia injusta, inequitativa, discriminatoria, que va en contravía de la política de desarrollo de talento humano formulada en el llamado a la Acción de Toronto ${ }^{11}$.

Llama la atención que más del $70 \%$ de los profesionales de salud son vinculados a través de agremiación sindical o por prestación de servicios, hecho que genera inestabilidad laboral y puede tener influencia negativa en la calidad de la atención; la Ley 1438 de $2011^{12}$, precisa que la contratación del personal misional permanente de las Instituciones públicas Prestadoras de Salud, no podrá hacerse a través de Cooperativas de trabajo asociado.

Es discriminatoria e injusta, la vinculación de personal con funciones misionales, bajo modalidades que niegan derechos laborales de carácter constitucional, conducta prohibida de manera taxativa por fallos de las Altas Cortes ${ }^{5}$. La contratación del personal de salud por agremiación sindical, antes llamadas cooperativas de trabajo asociado, ha desvirtuado los principios del cooperativismo y fomentado el empobrecimiento de los trabajadores; ellos además de los aportes a Seguridad Social deben cancelar las cuotas de administración correspondientes.

El que las profesiones femeninas registren los salarios más bajos denota inequidad e injusticia. Dichas diferencias son una de las formas más persistentes de desigualdad entre hombres y mujeres, y de discriminación por razones de sexo en el mundo del trabajo. El Convenio de la Organización Internacional del Trabajo $\mathrm{N}^{\circ} 100$ de 1951, ratificado por 154 países en el mundo, incluido Colombia, establece el principio de la igualdad de remuneración para trabajo de igual valor ${ }^{13}$.

La segregación laboral y/o distinción de puestos de trabajo ocupados por hombres y mujeres, así como la concentración en ciertos sectores de actividad y ocupaciones, lo mismo que la resistencia que encuentran las mujeres a la hora de acceder a puestos más cualificados y mejor remunerados, ha generado que las ocupaciones se devalúen social y económicamente a medida que se feminizan ${ }^{14}$.

La baja remuneración aunada a las formas de contratación excluyentes estimula la concentración de profesionales en las ciudades capitales y genera distribución ineficaz del personal sanitario entre las zonas urbanas, rurales y remotas, 
obstaculizando el acceso equitativo a los servicios y la cobertura sanitaria universal ${ }^{15}$.

En 2008 el Consejo Internacional de Enfermeras, la Federación internacional de hospitales, la Federación farmacéutica internacional, la Confederación mundial de fisioterapia, la Federación odontológica mundial, y la Asociación médica mundial, formularon directrices sobre incentivos financieros y no financieros para los profesionales de atención en salud ${ }^{16}$, resaltando la importancia del salario como factor motivacional y de satisfacción fundamental para los profesionales de la salud.

\section{Conclusiones}

En las IPS uno y dos, ubicadas en la ciudad capital, se concentra cerca de $80 \%$ de profesiones de salud; $53 \%$ son médicos, seguidos de enfermeras(os) y fisioterapeutas; las demás profesiones no superan, en ningún caso, el 4\%. Del total de participantes, 38,2\% tiene posgrado, $91.6 \%$ de ellos pertenecen a la disciplina que tradicionalmente ha alcanzado mayores niveles de desarrollo y de estatus social.

$27,5 \%$ de los profesionales en salud son empleados de planta, 14\% están vinculados por prestación de servicios y $58,5 \%$ a través de agremiación sindical. Bacteriología, Fonoaudiología, Medicina y Terapia ocupacional registran el mayor porcentaje de profesionales de planta, vinculación predominante en la IPS privada. Más del $70 \%$ de profesionales de Enfermería, Instrumentación quirúrgica, Terapia respiratoria y Fisioterapia prestan sus servicios a través de agremiación sindical.

Los salarios de las profesiones en salud son bajos, existiendo disparidad en la asignación básica mensual entre las disciplinas y al interior de las mismas; las IPS públicas de mayor complejidad ofrecen mejor remuneración y las profesiones tradicionalmente femeninas registran los salarios más bajos. La inequidad es mayor en el reconocimiento económico de los títulos de posgrado. No existen parámetros estandarizados para la determinación de salarios de las profesiones en salud, tampoco de los gerentes.

\section{Recomendaciones}

Establecer alianzas estratégicas con organizaciones profesionales para estructurar y llevar ante las instancias correspondientes un escalafón salarial que brinde igual trato a todas las profesiones en salud, en donde se reconozca el tiempo de experiencia, niveles de formación y los cargos ejercidos.

Gestionar ante directivos de IPS y organismos de control la vinculación, a las plantas de personal, de las profesiones que cumplen funciones misionales, según lo estipulado en el artículo 103 de la Ley 1438 de 2011.

\section{Referencias}

1. Cortés de Téllez R, Ramírez AL, Restrepo MP, Vargas BC. Declaración del Consejo Técnico Nacional de Enfermería "sobre el deterioro de las condiciones laborales del profesional de Enfermería en Colombia" En: encolombia.com. Revista de enfermería. [Internet] Disponible en: http://encolombia.com/medicina/revistas- medicas/enfermeria/vole-134/declaraciondel consejo tecnico

2. Dayrit MM, Dolea C, Dreesch N. Abordando la crisis de los Recursos Humanos para la Salud?: ¿ Hasta dónde hemos llegado? ¿Qué podemos esperar lograr al 2015? Rev Peru Med Exp Salud Pública. 2011 ;28(2): 327-336.

3. Organización Panamericana de la Salud. LLAMADO A LA ACCIÓN 2006-2015 Hacia una Década de Recursos Humanos en Salud para las Américas. Canada: Toronto 2005. [Internet] Disponible en: http://www. msal.gob.ar/ observatorio/images/stories/documentos_institucional/ decada\%20de\%20rhus/3-4-b-desafios toronto.pdf

4. Restrepo DA, Ortiz LC. Situación laboral de los profesionales en medicina y enfermería en Colombia: aproximaciones desde el Ingreso Base de Cotización al SGSSS. En: Ministerio de la Protección Social. Dirección General de Análisis y Política de Recursos Humanos. Boletín No. 2. Diciembre de 2010. [Internet] Disponible en: https://www.minsalud.gov.co/Documentos\%20 y\%20Publicaciones/APROXIMACI\%C3\% 93N\%20AL\%20IBC\%20PROFESIONALES\%20 EN\%20 MEDICINA\% 20Y\%20ENFERMER\%C3\%8DA.pdf

5. Arias Dolly. Características de profesionales y auxiliares de enfermería del Huila. 2010. av.enferm. [Internet]. 2012; 30( 2 ): 56-66. Available from: http://www.scielo. org.co/ scielo.php?script=sci_arttext\&pid=S0121 45002012000200006\&lng =en.

6. García Roa EM, Tapias Torrado L. EQUIDAD DE GÉNERO EN EL EMPLEO DEL SECTOR SALUD COLOMBIA 2008-2010. Pontificia Universidad Javeriana; 2010. p. 191. [Internet]. Disponible en: http://repository. javeriana.edu.co/bitstream/10554/871/1/pol151.pdf

7. Colombia. Ministerio de Educación Nacional Decreto 2277 de 1979. 1979; (Septiembre 14). [Internet]. Disponible en: http://www.mineducacion.gov.co/1621/ articles-103879_archivo_pdf.pdf

8. Giraldo ÁF. Atención Primaria en Salud (APS) ¿̇De regreso al pasado?. Rev. Fac. Nac. Salud Pública 2011. Vol.30 (1): 83-94. [Internet]. Disponible en: http://www. scielo.org.co/pdf/rfnsp/v30n 1/v30n 1 a 10

9. Organización Mundial de la Salud. Informe sobre la salud en el mundo 2006 - Colaboremos por la salud [Internet]. 2006 [cited 2014 May 7]. [Internet]. Disponible en: http://www.who.int/whr/2006/whr06_es.pdf?ua= 1

10. Organización Panamericana de la Salud. Indicadores Básicos 2011 Situación de Salud en Colombia. 2011 [cited 2014 May 26]; [Internet]. Disponible en: http:// medcontent.metapress.com/index/A65RM03P48 74243 N.pdf

11. Colombia. Ministerio de Salud y Protección Social. Informe de actividades 2012 - 2013 Sector Administrativo de Salud y Protección Social. 2013;1-225. [Internet]. Disponible en: http://www.minsalud.gov.co/Documentos $\% 20 y \% 20$ Publicaciones/Informe\%20al\%20Congreso \%202012-2013.pdf 
12. Congreso de la República de Colombia. LEY 14382011. Retrieved May 07, 2014, [Internet]. Disponible en: http:/ /www.secretariasenado.gov.co/senado/basedoc/ ley_1438_2011.htmleyes desde 1992.

13. Oficina Internacional del Trabajo. Declaracion relativa a los Principios y Derechos Fundamentales en el trabajo. C100 Convenio sobre igualdad de remuneracion, 1951. [Internet]. Disponible en: http://www.ilo.org/ wcmsp5/groups/public/_ed_norm/_declaration/ documents/publication/wcms_decl_fs_107_es.pdf

14. Fundación Innovación de la Economía Social, Innoves. Barreras sociales de las mujeres para emprender. Retrieved May 012, 2014 [Internet]. Disponible en: http:/ /www.emprendedorasenred.es/archivos/1331202164Estudio\%20Fempes.pdf

15. Buchan J, Couper ID, Tangcharoensathien V, Thepannya K, Jaskiewicz W, Perfilieva G, et al. Early implementation of WHO recommendations for the retention of health workers in remote and rural areas. Buul Word Heal Organ. 2013;(May):834-40. [Internet]. Disponible en: http://dx.doi.org/10.2471/BLT.13.119008

16. Directrices: Incentivos para los profesionales. Prepublicacion. 2008. P. 9-12. [Internet]. Disponible en: http://www.who.int/workforcealliance/documents/ Incentives_Guidelines\%20SP.pdf 